\title{
Efeito de diferentes níveis de proteína bruta e balanço eletrolítico sobre o desempenho, parâmetros sanguíneos e características ósseas de frangos de corte na fase de 36 a 42 dias de idade
}

\section{Effect of different levels of crude protein and electrolyte balance on performance, blood parameters and bone characteristics for broiler chickens in phase of 36 to 42 days old}

\author{
Franciele Clenice Navarini Giacobbo ${ }^{1}$; Elcio Silvério Klosowski²; Ricardo Vianna \\ Nunes ${ }^{2}$; Cleiton Pagliari Sangali³; Luís Daniel Giusti Bruno ${ }^{2 *}$; Cristiane Regina \\ Foltz Yoshihara ${ }^{4}$; Aparecida da Costa Oliveira ${ }^{5}$; Débora Cristiane Freitag ${ }^{6}$
}

\begin{abstract}
Resumo
O objetivo deste estudo foi avaliar o efeito de diferentes níveis de proteína bruta (PB) e balanço eletrolítico (BE) da ração de frangos de corte. Neste estudo foram utilizados 480 frangos de corte machos, da linhagem comercial Cobb 500, alimentados no período de 36 a 42 dias de idade com duas rações basais, uma com BE de 200 e outra com 240 mEq.kg-1 ${ }^{-1}$ combinadas com níveis de PB de 18,00, 17,28, 16,56 e $15,84 \%$. A redução nos níveis de $\mathrm{PB}$ teve efeito linear $(\mathrm{P}<0,01)$ crescente sobre a conversão alimentar das aves (BE 200 e 240), mesmo com a suplementação de aminoácidos industriais. Para o ganho de peso, a redução nos níveis de $\mathrm{PB}$ teve efeito linear $(\mathrm{P}<0,01)$ decrescente para as aves consumindo ração com BE de $240 \mathrm{mEq}$. $\mathrm{kg}^{-1}$ e efeito quadrático $(\mathrm{P}<0,05)$ para aquelas que consumiram ração com $\mathrm{BE}$ de $200 \mathrm{mEq}$. $\mathrm{kg}^{-1}$ sendo o nível de $17,54 \%$ o que proporcionou o melhor ganho de peso das aves. Houve efeito linear $(\mathrm{P}<0,05)$ da redução nos níveis de $\mathrm{PB}$ sobre os valores plasmáticos de sódio (BE200) e cloro (BE240) e efeito quadrático $(\mathrm{P}<0,05)$ sobre a concentração plasmática de potássio $(\mathrm{BE} 200)$ das aves, sendo o nível de $17,05 \%$ o que proporcionou os menores valores de potássio. Para os níveis plasmáticos de acido úrico, proteína total e cálcio e para o desenvolvimento ósseo das aves, a redução nos níveis de $\mathrm{PB}$ não teve efeito em nem um dos níveis de $\mathrm{BE}$ estudados. A suplementação com os sais bicarbonato de sódio e cloreto de potássio não se mostrou eficiente em melhorar as características de desempenho das aves, nos valores de $\mathrm{BE}$ estudados, visto que não foram observadas melhoras de desempenho com aumento do BE das dietas de 200 para $240 \mathrm{mEq} . \mathrm{kg}^{-1}$.

Palavras-chave: Equilíbrio ácido-básico, osso, sangue, teor proteico
\end{abstract}

\footnotetext{
${ }^{1}$ Zootecnista, Cooperativa Agroindustrial Copagril, Marechal Cândido Rondon, PR. E-mail: frannavarini@hotmail.com

2 Profs., Centro de Ciências Agrárias, Universidade Estadual do Oeste do Paraná, UNIOESTE, Marechal Cândido Rondon, PR. E-mail: elciosk1@yahoo.com.br; nunesrv@hotmail.com; luis.bruno@unioeste.br

${ }^{3}$ Discente do Curso de Doutorado em Zootecnia, Universidade Estadual de Maringá, UEM, Maringá, PR. E-mail: sangalicp@ hotmail.com

${ }^{4}$ Discente do Curso de Graduação em Zootecnia, UNIOESTE, Marechal Cândido Rondon, PR. E-mail: cristianefoltz@hotmail. com

${ }^{5}$ Discente do Curso de Doutorado em Zootecnia, UniversidadeFederal da Paraíba,UFPB,Areia, PB.E-mail: aparecidacostaoliveira@ gmail.com

${ }^{6}$ Discente do Curso de Mestrado em Zootecnia, UNIOESTE, Marechal Cândido Rondon, PR. E-mail: deborafreitag@gmail.com

* Autor para correspondência
} 


\begin{abstract}
The aim of this study was to evaluate the effect of different levels of crude protein (CP) and electrolyte balance (EB) of the feed of broilers. 480 male broiler of Cobb 500 strain were fed in the period 36 to 42 days of age with two basal diets, one with EB 200 and another with $240 \mathrm{mEq} . \mathrm{kg}^{-1}$, combined with $\mathrm{CP}$ levels of $18.00,17.28,16.56$ and $15.84 \%$. The reduction in $\mathrm{CP}$ levels had growing linear effect (P $<0.01$ ) on feed conversion of birds (BE 200 and 240) even with the supplementation of industrial amino acids. For weight gain, reduced levels of $\mathrm{CP}$ had decreasing linear effect $(\mathrm{P}<0.01)$ to birds consuming diets with $\mathrm{EB}$ of $240 \mathrm{mEq} . \mathrm{kg}^{-1}$ and quadratic effect $(\mathrm{P}<0.05)$ for those who consumed ration with $\mathrm{EB}$ than $200 \mathrm{mEq} . \mathrm{kg}^{-1}$ being the level of $17.54 \%$, which resulted in better weight gain of birds. There was linear effect $(\mathrm{P}<0.05)$ of reduction in $\mathrm{CP}$ levels on the plasmatic values of sodium $(\mathrm{EB} 200)$ and chlorine (EB240) and quadratic effect $(\mathrm{P}<0.05)$ on plasmatic concentration of potassium (EB200) of birds, being the level of $17.05 \%$, which provided the lower potassium values. For the plasma levels of uric acid, total protein and calcium, and bone development, reduction in the levels of CP had no effect on neither one of EB levels studied. Supplementation with bicarbonate salts of sodium and potassium chloride was not effective in improving the performance characteristics the birds, in the values of electrolyte balance studied, since there were no performance improvements with increase the electrolytic balance of the diets of 200 to $240 \mathrm{mEq} \cdot \mathrm{kg}^{-1}$.
\end{abstract}

Key words: Acid basic balance, blood, bone, protein level

\section{Introdução}

Nas condições de clima tropical e mesmo subtropical, como é o caso de algumas regiões do Brasil, não é raro o registro de temperatura e umidade do ar acima da zona de conforto térmico das aves, o que muitas vezes acaba limitando à expressão do potencial genético para produção.

Contudo, algumas medidas podem ser tomadas para minimizar as perdas decorrentes do estresse calórico, podendo-se citar, entre outras, modificações ambientais por meio de sistemas de climatização (SARTOR et al., 2003), ou modificações no manejo nutricional, como a manipulação da proteína e da energia da dieta assim como, o uso de eletrólitos via água de bebida ou nas rações das aves (BORGES; MAIORKA; SILVA, 2003).

Entre os principais sais utilizados destacamse o cloreto de potássio $(\mathrm{KCl})$, o bicarbonato de sódio $\left(\mathrm{NaHCO}_{3}\right)$, o cloreto de cálcio $\left(\mathrm{CaCl}_{2}\right)$ e o cloreto de amônio $\left(\mathrm{NH}_{4} \mathrm{Cl}_{2}\right)$, que são adicionados às rações de verão, alterando o balanço eletrolítico das dietas. Esta incorporação de cátions e ânions às rações é usualmente expressa em mEq. $\mathrm{kg}^{-1}$ de ração (MONGIN, 1981).

Outra forma de minimizar o estresse por calor é o ajuste das dietas com redução da proteína bruta (PB) e suplementação com aminoácidos industriais, permitindo que as aves tenham balanço aminoacidico de acordo com suas exigências reais. Essa prática possibilita a redução da excreção de nitrogênio, associada ao menor calor gerado pelo catabolismo de aminoácidos ingeridos.

A redução da proteína bruta da dieta deve ser realizada com cautela, de modo a garantir a suplementação dos aminoácidos essenciais e até mesmo os não essenciais, maximizando o desempenho das aves. Assim, o estudo do balanço eletrolítico (BE), juntamente com a redução da $\mathrm{PB}$ da ração, torna-se uma ferramenta adicional em rações para frangos de corte criados em condições de altas temperaturas, sendo que a proporção de eletrólitos precisa ser avaliada e adequada no sentido de contribuir para este importante segmento da avicultura brasileira.

Outro ponto a ser considerado é o possível efeito do balanço eletrolítico da dieta no desenvolvimento ósseo das aves. De acordo com Oliveira, Arantes e Stringhini (2010), a alteração do balanço eletrolítico da dieta pode influenciar no desenvolvimento dos ossos dos frangos, sendo importante levar este fator em consideração quando do estudo da influência do balanço eletrolítico no desenvolvimento das aves. 
Desta forma, o objetivo deste trabalho foi o de avaliar o efeito de diferentes níveis de $\mathrm{PB}$ e BE da ração de frangos de corte no período 36 a 42 dias de idade com base no desempenho, parâmetros sanguíneos e desenvolvimento ósseo das aves.

\section{Material e Métodos}

O experimento foi realizado no Setor de Avicultura do Núcleo de Estações Experimentais da Universidade Estadual do Oeste do Paraná UNIOESTE, Campus de Marechal Cândido Rondon, Estado do Paraná. Neste estudo foram utilizados 480 frangos de corte machos, da linhagem comercial Cobb 500, durante o período de 36 a 42 dias de idade. Ate atingirem a idade de 35 dias de idade, as aves foram alimentadas com ração à base de milho e farelo de soja, formulada segundo recomendações de Rostagno et al. (2011). Aos 35 dias de idade as aves foram distribuídas nas unidades experimentais de acordo com a massa corporal (SAKOMURA; ROSTAGNO, 2007).

As aves foram alojadas em galpão de alvenaria, com pé direito de 3,0 metros, contendo muretas laterais de $0,50 \mathrm{~m}$, cortinas, tela, cobertura com telhas de cerâmica francesa, provida de lanternim e subdividido em 50 boxes com dimensão de 1,00 $\mathrm{x} 1,35 \mathrm{~m}$. A ração e a água foram fornecidas $a d$ libitum durante todo o período experimental, sendo utilizados comedouros tipo tubular e bebedouros de nipple. O programa de iluminação utilizado foi constante, com 24 horas de luminosidade (luz natural e artificial).

As condições ambientais do galpão foram monitoradas diariamente às 8:00, 10:00, 12:00, $14: 00,16: 00$ e às 18:00 $\mathrm{h}$, por meio de um termo higrômetro digital, com sensor externo de temperatura, que foi utilizado como termômetro de globo negro (TGN). O TGN foi constituído de uma esfera de polietileno com diâmetro de 15 $\mathrm{cm}$, com superfície externa pintada de preto fosco, disposto à altura do centro médio de massa das aves, distribuídos aleatoriamente em pontos estratégicos do galpão. Estas medidas foram utilizadas para calcular o índice de temperatura de globo negro e umidade (ITGU), caracterizando o ambiente térmico da instalação, conforme preconizado por Buffington et al. (1981).

O delineamento experimental utilizado foi o inteiramente casualizado em um esquema fatorial 2 x 4 (dois balanços eletrolíticos - 200 e 240 em mEq. $\mathrm{kg}^{-1}-\mathrm{x}$ quatro níveis de proteína bruta $-15,84 \%$; $16,56 \% ; 17,28 \%$ e $18 \%$ ), com cinco repetições, sendo alojadas 12 aves por unidade experimental, perfazendo uma densidade de 7,69 aves $/ \mathrm{m}^{2}$.

As dietas experimentais, a base de milho, farelo de soja e glúten de milho, foram formuladas com base na composição dos alimentos e recomendações nutricionais propostas por Rostagno et al. (2011), com exceção da proteína bruta, que foi reduzida em $0 \%, 4 \%, 8 \%$ e $12 \%$ (Tabela 1 ). Para manter a relação entre os aminoácidos e a lisina, as dietas com redução de proteína bruta foram suplementadas com aminoácidos industriais.

O BE foi calculado com base nos níveis de $\mathrm{Na}$, $\mathrm{K}$ e $\mathrm{Cl}$ dos alimentos contidos nas rações, conforme proposto por Mongin (1981) utilizando-se a seguinte equação:

$$
\mathrm{BE}=(\mathrm{Na} / 23+\mathrm{K} / 39-\mathrm{Cl} / 35,5) \times 100
$$

em que $\mathrm{Na}, \mathrm{K}$ e $\mathrm{Cl}$ são as quantidades de sódio, potássio e cloro, respectivamente, presentes em cada um dos alimentos. Para garantir os BE de 200 e $240 \mathrm{em} \mathrm{mEq.} \mathrm{kg}^{-1}$, foi utilizado o cloreto de sódio e o bicarbonato de sódio.

O consumo de ração, o ganho de peso e a conversão alimentar foram determinados em todas as aves de cada tratamento. Para isto, foram pesadas as aves e a ração no início e no final do período experimental. O consumo médio de ração foi calculado pela diferença entre a ração fornecida e a sobra do comedouro, em cada unidade experimental. O ganho de peso-foi calculado como a diferença entre os pesos inicial e final das aves em cada unidade experimental. A conversão alimentar foi obtida dividindo-se o consumo médio da ração pelo ganho de peso médio das aves de cada unidade experimental. 
Tabela 1. Composição percentual das dietas experimentais.

\begin{tabular}{|c|c|c|c|c|c|c|c|c|}
\hline \multirow{2}{*}{ Ingredientes (\%) } & \multicolumn{8}{|c|}{ Tratamentos } \\
\hline & 1 & 2 & 3 & 4 & 5 & 6 & 7 & 8 \\
\hline Milho & 64,00 & 66,38 & 68,75 & 71,12 & 63,84 & 66,22 & 68,60 & 70,82 \\
\hline Farelo de soja & 28,51 & 26,35 & 24,20 & 22,04 & 28,53 & 26,38 & 24,22 & 22,09 \\
\hline Glúten de milho & 1,159 & 1,167 & 1,175 & 1,183 & 1,159 & 1,167 & 1,174 & 1,182 \\
\hline Calcário calcítico & 1,294 & 1,365 & 1,317 & 1,329 & 1,295 & 1,306 & 1,317 & 1,329 \\
\hline Fosfato bicálcico & 0 & 0 & 0 & 0 & 0 & 0 & 0 & 0,432 \\
\hline Óleo de soja & 3,793 & 3,402 & 3,009 & 2,614 & 3,846 & 3,455 & 3,062 & 2,716 \\
\hline Cloreto de sódio & 0,396 & 0,325 & 0,254 & 0,182 & 0,161 & 0,089 & 0,018 & 0,020 \\
\hline Bicarbonato de sódio & 0,082 & 0,178 & 0,275 & 0,371 & 0,396 & 0,492 & 0,589 & 0,643 \\
\hline Cloreto de colina $60 \%$ & 0,042 & 0,050 & 0,059 & 0,067 & 0,042 & 0,051 & 0,059 & 0,068 \\
\hline DL - Metionina 99\% & 0,248 & 0,266 & 0,285 & 0,303 & 0,248 & 0,266 & 0,285 & 0,303 \\
\hline $\mathrm{L}$ - Lisina $\mathrm{HCl}$ & 0,225 & 0,292 & 0,358 & 0,425 & 0,225 & 0,291 & 0,358 & 0,424 \\
\hline L - Treonina & 0,078 & 0,108 & 0,139 & 0,169 & 0,078 & 0,108 & 0,138 & 0,168 \\
\hline Triptofano & 0 & 0 & 0,005 & 0,017 & 0 & 0 & 0,005 & 0,017 \\
\hline Antioxidante ${ }^{1}$ & 0,012 & 0,012 & 0,012 & 0,012 & 0,012 & 0,012 & 0,012 & 0,012 \\
\hline Suplemento mineral $^{2}$ & 0,050 & 0,050 & 0,050 & 0,050 & 0,050 & 0,050 & 0,050 & 0,050 \\
\hline Supl. vitamínico ${ }^{3}$ & 0,100 & 0,100 & 0,100 & 0,100 & 0,100 & 0,100 & 0,100 & 0,100 \\
\hline Promot. crescimento ${ }^{4}$ & 0,010 & 0,010 & 0,010 & 0,010 & 0,010 & 0,010 & 0,010 & 0,010 \\
\hline $\begin{array}{l}\text { Energia }(\mathrm{kcal} / \mathrm{kg}) \text { e nutrientes } \\
(\%)\end{array}$ & \multicolumn{8}{|c|}{ Composição calculada } \\
\hline Energia metabolizável & 3.150 & 3.150 & 3.150 & 3.150 & 3.150 & 3.150 & 3.150 & 3.150 \\
\hline Proteína bruta & 18,00 & 17,28 & 16,56 & 15,84 & 18,00 & 17,28 & 16,56 & 15,84 \\
\hline Cálcio & 0,763 & 0,763 & 0,763 & 0,763 & 0,763 & 0,763 & 0,763 & 0,763 \\
\hline Fósforo disponível & 0,380 & 0,380 & 0,380 & 0,380 & 0,380 & 0,380 & 0,380 & 0,380 \\
\hline Lisina digestível & 1,017 & 1,017 & 1,017 & 1,017 & 1,017 & 1,017 & 1,017 & 1,017 \\
\hline Metionina digestível & 0,488 & 0,497 & 0,506 & 0,514 & 0,488 & 0,497 & 0,506 & 0,514 \\
\hline Met + cis digestível & 0,732 & 0,732 & 0,732 & 0,732 & 0,732 & 0,732 & 0,732 & 0,732 \\
\hline Triptofano digestível & 0,189 & 0,178 & 0,173 & 0,173 & 0,189 & 0,178 & 0,173 & 0,173 \\
\hline Treonina digestível & 0,661 & 0,661 & 0,661 & 0,661 & 0,661 & 0,661 & 0,661 & 0,661 \\
\hline Arginina digestível & 1,091 & 1,030 & 0,968 & 0,907 & 1,091 & 1,030 & 0,968 & 0,907 \\
\hline Sódio & 0,190 & 0,190 & 0,190 & 0,190 & 0,190 & 0,190 & 0,190 & 0,205 \\
\hline Potássio & 0,767 & 0,731 & 0,694 & 0,658 & 0,767 & 0,731 & 0,694 & 0,681 \\
\hline Cloro & 0,303 & 0,268 & 0,233 & 0,197 & 0,162 & 0,127 & 0,091 & 0,100 \\
\hline $\mathrm{BE} \mathrm{mEq} \cdot \mathrm{kg}^{-1}$ & 200,0 & 200,0 & 200,0 & 200,0 & 240,0 & 240,0 & 240,0 & 240,0 \\
\hline
\end{tabular}

${ }^{1}$ BHT (Hidroxi Butil Tolueno); ${ }^{2}$ Suplemento mineral, conteúdo: $\mathrm{Mg}-16,0 \mathrm{~g} ; \mathrm{Fe}-100,00 \mathrm{~g} ; \mathrm{Zn}-100,0$ g; Cu - 2,0 g; Co - 2,0 g; I - 2,0 g; e Veículo q. s. p. - 1.000 g; ${ }^{3}$ Suplemento vitamínico, conteúdo: vit. A - 10.000.000 UI; vit. D3 - 2.000 .000 UI; vit. E - 30.000 UI; vit. B1 - 2,0 g; vit. B6 - 4,0 g; Ac. Pantotênico- 12,0 g; Biotina- 0,10 g; vit. K3 - 3,0 g; Ac. fólico - 1,0 g; Ac. Nicotínico- 50,0 g; vit. B12 - 15.000 mcg; Selênio- 0,25 g; e Veículo q. s. p. -1.000 g. ${ }^{4}$ Avilamicina $10 \%$.

Fonte: Elaboração dos autores.

O soro sanguíneo de duas ave (10 aves por tratamento) com $\pm 10 \%$ a massa corporal média de cada unidade experimental foi coletado no $42^{\circ}$ dia de idade segundo metodologia descrita por Conhalato et al. (2000). O sangue foi colocado em tubos de ensaio e, após, centrifugado, durante quinze minutos a $2000 \mathrm{rpm}$, para separação do soro que foi imediatamente congelado. Posteriormente, foram feitas as análises de proteínas totais, ácido úrico, cálcio, potássio, sódio e cloro, utilizando "kits" reagentes.

Para avaliação do crescimento ósseo foi utilizada a metodologia de Bruno et al. (2000), sendo 
sacrificadas 2 aves por boxe para a coleta dos ossos longos (fêmur e tíbia) direitos.

Após a coleta, os ossos foram congelados e, posteriormente colocados em água fervente por aproximadamente 10 segundos para ser retirado todo tecido muscular aderido. Após a retirada do tecido muscular, os ossos foram mergulhados em éter de petróleo por um período de 24 horas para serem desengordurados, e então secos em estufa de ventilação forçada a $40^{\circ} \mathrm{C}$ por 24 horas. Ao final da secagem em estufa os mesmos foram estocados para a realização das análises referentes ao desenvolvimento ósseo.

Para mensuração da massa do osso foi utilizada uma balança analítica de precisão $(0,0001 \mathrm{~g})$. Tanto o comprimento quanto a espessura óssea foram mensurados com o auxílio de um paquímetro $(0,01 \mathrm{~mm})$. O comprimento foi medido tomandose a maior distância entre as epífises, e a espessura tomando-se o ponto central do osso, sendo que as mensurações foram feitas sempre nos mesmos pontos em todos os ossos.

Com a massa do osso seco e seu comprimento foi calculado o índice de Seedor (peso do osso expresso em mg, dividido pelo comprimento do osso expresso em $\mathrm{mm}$ ), proposto por Seedor, Quarruccio e Thompson (1991) e que é utilizado como um indicativo da densidade óssea. Quanto maior o índice de Seedor maior a densidade da peça óssea e vice-versa.

As análises estatísticas dos dados obtidos foram realizadas pelo programa SAEG - Sistema para Análises Estatísticas e Genéticas (UFV, 2005), sendo adotado o nível de significância de 5\% em todos os testes de hipóteses.

Por interesse do estudo, optou-se pelo desdobramento dos níveis de PB dentro de cada $\mathrm{BE}$, independente da interação ter sido significativa. Desta forma, os efeitos dos níveis de PB sobre as características avaliadas foram testados pelo teste F da análise de variância, com posterior análise de regressão polinomial. $\mathrm{Na}$ comparação das médias dos tratamentos para cada BE foi utilizado o teste $\mathrm{F}$ da análise de variância.

\section{Resultados e Discussão}

Durante o período experimental, os valores de temperatura mínima, média e máxima foram de 24,2 , 28,0 , e $34,8^{\circ} \mathrm{C}$, respectivamente (Tabela 2). Oliveira et al. (2006) indicam $25^{\circ} \mathrm{C}$ como a temperatura de conforto para animais entre 1 a 49 dias de idade e a temperatura do ar de $35^{\circ} \mathrm{C}$ como sendo estressante para os frangos de corte nesta idade.

Tabela 2. Médias dos elementos climáticos e do índice de temperatura de globo negro e umidade (ITGU) observados durante o período experimental.

\begin{tabular}{lc}
\hline Variáveis Climáticas & $36-42$ dias \\
\hline Temperatura do ar $\left({ }^{\circ} \mathrm{C}\right)$ & 28,0 \\
Temperatura máxima $\left({ }^{\circ} \mathrm{C}\right)$ & 34,8 \\
Temperatura mínima $\left({ }^{\circ} \mathrm{C}\right)$ & 24,2 \\
Umidade relativa $(\%)$ & 64,0 \\
Temperatura de globo negro $(\%)$ & 28,8 \\
ITGU & 77,7 \\
\hline
\end{tabular}

Fonte: Elaboração dos autores.

Contudo, Buffington et al. (1981), destacaram que, nas condições de clima tropical, o ITGU é considerado mais adequado na avaliação do ambiente térmico já que este índice considera, além da temperatura de bulbo seco, os efeitos da umidade relativa, da radiação e da velocidade do ar. No 
presente estudo, o valor médio do ITGU foi de 77,7 caracterizando condição de desconforto térmico para as aves, já que, de acordo Medeiros et al. (2005), para frangos de corte dos 22 aos 42 dias de idade, o ambiente considerado confortável é o que apresenta temperatura de $26^{\circ} \mathrm{C}$ e ITGU variando de 69 a 77, e o ambiente considerado quente é o que apresenta temperatura de $32^{\circ} \mathrm{C}$ a $36^{\circ} \mathrm{C}$ e ITGU de 78 a 88.

Foram observados efeito linear $(\mathrm{P}<0,01)$ crescente dos níveis de $\mathrm{PB}$ sobre a conversão alimentar, para as aves que consumiram ração com $\mathrm{BE}$ de 200 e $240 \mathrm{mEq}$. kg-1 (Tabela 3). Para o ganho de peso, a redução nos níveis de $\mathrm{PB}$ teve efeito linear $(\mathrm{P}<0,01)$ decrescente para as aves consumindo ração com $\mathrm{BE}$ de $240 \mathrm{mEq}$. $\mathrm{kg}^{-1}$ e efeito quadrático $(\mathrm{P}<0,05)$ para aquelas que consumiram ração com BE de $200 \mathrm{mEq}$. $\mathrm{kg}^{-1}$ sendo o nível de 17,54\% o que proporcionou o melhor ganho de peso das aves (Tabela 4). Para o consumo de ração, a redução nos níveis de $\mathrm{PB}$ teve efeito linear $(\mathrm{P}<0,05)$, decrescente, apenas para as aves recebendo dieta com BE de 240 mEq. $\mathrm{kg}^{-1}$.

Tabela 3. Desempenho de frangos de corte, de 36 a 42 dias de idade, alimentados com rações com diferentes níveis de proteína bruta (PB) e balanços eletrolíticos (BE).

\begin{tabular}{|c|c|c|c|c|c|c|}
\hline \multirow{2}{*}{$\begin{array}{l}\mathrm{PB}(\%) \\
\mathrm{BE}\end{array}$} & \multicolumn{2}{|c|}{$\begin{array}{l}\text { Consumo de ração } \\
(\mathrm{kg})\end{array}$} & \multicolumn{2}{|c|}{$\begin{array}{c}\text { Ganho de peso } \\
(\mathrm{kg})\end{array}$} & \multicolumn{2}{|c|}{$\begin{array}{l}\text { Conversão alimentar } \\
(\mathrm{kg})\end{array}$} \\
\hline & 200 & 240 & 200 & 240 & 200 & 240 \\
\hline 18,00 & 0,881 & 0,879 & 0,504 & 0,497 & 1,666 & 1,645 \\
\hline 17,28 & 0,883 & 0,875 & 0,512 & 0,486 & 1,784 & 1,731 \\
\hline 16,56 & 0,915 & 0,838 & 0,473 & 0,443 & 1,865 & 1,975 \\
\hline 15,84 & 0,839 & 0,818 & 0,400 & 0,410 & 2,202 & 2,146 \\
\hline Média & $0,879^{a}$ & $0,852^{\mathrm{a}}$ & $0,472^{\mathrm{a}}$ & $0,459^{\mathrm{a}}$ & $1,880^{\mathrm{a}}$ & $1,873^{\mathrm{a}}$ \\
\hline Efeito & ns & $\mathrm{L}^{*}$ & $\mathrm{Q}^{*}$ & $\mathrm{~L}^{* *}$ & $\mathrm{~L}^{* *}$ & $\mathrm{~L}^{* *}$ \\
\hline $\mathrm{CV}(\%)$ & \multicolumn{2}{|c|}{6,92} & \multicolumn{2}{|c|}{7,19} & \multicolumn{2}{|c|}{2,02} \\
\hline
\end{tabular}

$\mathrm{BE}=$ balanços eletrolíticos (mEq.kg); $\mathrm{CV}=$ coeficiente de variação; ${ }^{\text {ab }}$ Médias seguidas pela mesma letra para cada característica avaliada, na linha, não diferem entre si pelo teste $\mathrm{F}(\mathrm{P} \geq 0,05)$; ns = não significativo pelo teste $\mathrm{F}(\mathrm{P} \geq 0,05)$; $\mathrm{Q}^{*}=$ efeito quadrático, pelo teste $\mathrm{F}$ da regressão $(\mathrm{P}<0,05)$; $\mathrm{L}^{*}=$ efeito linear, pelo teste $\mathrm{F}$ da regressão $(\mathrm{P}<0,05)$.

Fonte: Elaboração dos autores.

Tabela 4. Equações de regressão de desempenho zootécnico de frangos de corte de 36 a 42 dias de idade alimentados com rações com diferentes níveis de proteína bruta (PB) e balanços eletrolíticos (BE).

\begin{tabular}{|c|c|c|c|c|}
\hline Parâmetro & Equação de regressão & $\mathrm{R}^{2}$ & Ponto Máx & PB \\
\hline CR240 & $0,33123+0,03080 * \mathrm{~PB}$ & 0,89 & & \\
\hline GP200 & $-11,91197+1,41698 *$ PB- $0,0404 * \mathrm{~PB}^{2}$ & 0,99 & 0,51 & 17,54 \\
\hline GP240 & $-0,26113+0,04255^{*} \mathrm{~PB}$ & 0,93 & & \\
\hline CA200 & $-5,87353-0,236 * \mathrm{~PB}$ & 0,84 & & \\
\hline CA240 & $6,01394-0,24459 * \mathrm{~PB}$ & 0,96 & & \\
\hline
\end{tabular}

CR - consumo de ração; GP - ganho de peso (kg); CA - conversão alimentar (kg); Máx - Máximo.

Fonte: Elaboração dos autores.

Em trabalho com frangos de corte na fase de 22 a 42 dias de idade, Oliveira et al. (2010) não verificaram perdas no desempenho das aves com a redução nos níveis de PB $(21,6 ; 20,6 ; 19,6 ; 18,6$ e 17,6\%). De acordo com os autores, rações com níveis proteicos reduzidos suplementadas com aminoácidos de forma a atender as necessidades das aves, aproximando-se do perfil ideal recomendado, 
são eficientes em proporcionar aos frangos o mesmo desempenho obtido com a ração com o nível proteico mais elevado (controle). Em trabalho recente com frangos de corte na fase de 21 a 35 dias de idade, Gomide et al. (2011) também observaram ser possível reduzir a proteína de rações sem prejudicar o desempenho das aves, desde que as rações sejam suplementadas com aminoácidos industriais.

Por outro lado, resultados de vários trabalhos na literatura apontam para uma piora no desempenho das aves com a redução no teor de $\mathrm{PB}$ da ração (JIANG; WALDROUP; FRITTS, 2005; KAMRAN et al., 2008; MATOS et al., 2011; OLIVEIRA et al., 2011). Em estudo recente, Vasconcellos et al. (2010) apontam perdas no desempenho e aumento na gordura abdominal com a redução proteica (21, 19, 17 e 15\%) na fase de 22 a 42 dias de idade, mesmo suplementando as dietas com aminoácidos essenciais até o nível de exigência preconizado por Rostagno et al. (2005).

Estes resultados sugerem cautela quanto à decisão por formulações com menor teor de proteína bruta, mesmo com a suplementação de aminoácidos industriais, visto que foi observada queda significativa de algumas características de desempenho, quando se utilizou a redução da PB.

Não foram observadas diferenças $(P \geq 0,05)$ entre as médias dos tratamentos com BE de 200 e $240 \mathrm{mEq}$. $\mathrm{kg}^{-1}$, para os parâmetros de desempenho avaliados (Tabela 3). Tais resultados diferem dos encontrados por Vieites et al. (2011a), que observaram efeito quadrático no ganho de peso das aves recebendo rações com BE variando de 200 a $400 \mathrm{mEq} \cdot \mathrm{kg}^{-1}$, sendo o nível de $300 \mathrm{mEq} \cdot \mathrm{kg}^{-1}$ o que proporcionou o melhor ganho de peso. Contudo, deve-se ressaltar que esses pesquisadores trabalharam com níveis de $\mathrm{BE}$ mais elevados do que os utilizados no presente estudo, o que ocasionou a diferença no desempenho, o que não ocorreu no presente experimento.

A redução nos níveis de $\mathrm{PB}$ teve efeito linear $(\mathrm{P}<0,05)$ sobre os níveis de sódio (BE200) e cloro $(\mathrm{BE} 240)$ e efeito quadrático $(\mathrm{P}<0,05)$ sobre a concentração plasmática de potássio (BE200) das aves (Tabela 5), sendo o nível de 17,05\% o que proporcionou os menores valores de potássio (Tabela 6). Para os níveis plasmáticos de ácido úrico, proteína total e cálcio, a redução nos níveis de $\mathrm{PB}$ não teve efeito em nem um dos $\mathrm{BE}$ estudados. Também não foram observadas diferenças entre as médias dos tratamentos com BE de 200 e $240 \mathrm{mEq}$. $\mathrm{kg}^{-1}$ para os parâmetros sanguíneos analisados, exceto para os níveis de potássio em que foi observado um aumento significativo $(\mathrm{P}<0,05)$ com a elevação do nível de BE de 200 para $240 \mathrm{mEq}$. $\mathrm{kg}^{-1}$ (Tabela 5).

Matos et al. (2009), ao trabalharem com dois níveis $(15,03$ e $18,03 \%)$ de $\mathrm{PB}$ e correção do $\mathrm{BE}$ para 250 não encontraram diferenças entre as médias dos tratamentos com PB de 15,03 e 18,03\% para as concentrações plasmáticas de sódio, potássio e cloro de frangos de corte aos 42 dias de idade. Em estudo mais recente, Vieites et al. (2011b) trabalharam com 8 níveis de BE variando de 0 a 350 e dois níveis (20 e 23\%) de PB e também não observaram efeito dos níveis de $\mathrm{PB}$ sobre os valores plasmáticos de cálcio e proteína total, contudo os autores observaram elevação de 6,52 para $6,78 \mathrm{mg} / \mathrm{dL}$ quando foi reduzido o teor de $\mathrm{PB}$ de 23 para $20 \%$. Com relação aos níveis de $\mathrm{BE}$ os autores encontraram efeito quadrático $(\mathrm{P}<0,05)$ sobre os valores de proteína total do sangue das aves, para os dois níveis de PB estudados, e queda linear $(\mathrm{P}<0,05)$ nos níveis plasmáticos de cálcio das aves recebendo dietas com $23 \%$ de PB. De acordo com Vieites et al. (2004) o excesso de cálcio em aves indica alterações do equilíbrio ácido-básico, resultado de uma resposta do organismo animal que inclui ações hormonais e mecanismos respiratórios compensatórios, culminando com o ajuste renal. Segundo Davenport (1972), quando o rim compensa distúrbios do equilíbrio ácido-básico, ocorre alteração na excreção de eletrólitos, modificando os padrões eletrolítico e ácido-básico do sangue. 
Tabela 5. Níveis plasmáticos de ácido úrico, proteína total, cálcio, sódio, potássio e cloro em frangos de corte, de 36 a 42 dias de idade, alimentados com rações com diferentes balanços eletrolíticos (BE) e níveis de proteína bruta (PB).

\begin{tabular}{|c|c|c|c|c|c|c|}
\hline \multirow{2}{*}{$\begin{array}{l}\mathrm{PB}(\%) \\
\mathrm{BE}\end{array}$} & \multicolumn{2}{|c|}{$\begin{array}{l}\text { Acido úrico } \\
\left(\mathrm{mg} \cdot \mathrm{dL}^{-1}\right)\end{array}$} & \multicolumn{2}{|c|}{$\begin{array}{l}\text { Proteína total } \\
\left(\mathrm{mg} \cdot \mathrm{dL}^{-1}\right)\end{array}$} & \multicolumn{2}{|c|}{$\begin{array}{l}\text { Cálcio } \\
\left(\mathrm{mg} \mathrm{dL}^{-1}\right)\end{array}$} \\
\hline & 200 & 240 & 200 & 240 & 200 & 240 \\
\hline 18,00 & 2,47 & 2,43 & 2,40 & 2,61 & 19,66 & 18,35 \\
\hline 17,28 & 2,42 & 2,42 & 2,38 & 2,52 & 18,71 & 20,12 \\
\hline 16,56 & 2,51 & 2,61 & 2,18 & 2,61 & 19,19 & 19,90 \\
\hline 15,84 & 2,67 & 2,20 & 2,46 & 2,25 & 21,26 & 20,39 \\
\hline Média & 2,52 & 2,42 & 2,36 & 2,50 & 19,71 & 19,65 \\
\hline Efeito & ns & ns & ns & ns & ns & ns \\
\hline $\mathrm{CV}(\%)$ & \multicolumn{2}{|c|}{13,60} & \multicolumn{2}{|c|}{9,97} & \multicolumn{2}{|c|}{10,50} \\
\hline PB (\%) & \multicolumn{2}{|c|}{$\begin{array}{c}\text { Sódio } \\
\left(\mathrm{mg.dL}^{-1}\right)\end{array}$} & \multicolumn{2}{|c|}{$\begin{array}{l}\text { Potássio } \\
\left(\mathrm{mg} \mathrm{dL}^{-1}\right)\end{array}$} & \multicolumn{2}{|c|}{$\begin{array}{c}\text { Cloro } \\
\left(\mathrm{mg} \cdot \mathrm{dL}^{-1}\right)\end{array}$} \\
\hline $\mathrm{BE}$ & 200 & 240 & 200 & 240 & 200 & 240 \\
\hline 18,00 & 134,66 & 138,06 & 6,49 & 6,56 & 109,08 & 115,65 \\
\hline 17,28 & 136,61 & 137,72 & 6,15 & 6,39 & 111,82 & 116,30 \\
\hline 16,56 & 137,33 & 135,95 & 6,10 & 6,29 & 119,33 & 111,20 \\
\hline 15,84 & 137,92 & 134,63 & 6,34 & 6,46 & 115,18 & 114,86 \\
\hline Média & $136,73^{\mathrm{a}}$ & $136,60^{\mathrm{a}}$ & $6,27^{b}$ & $6,43^{\mathrm{a}}$ & $114,05^{\mathrm{a}}$ & $115,43^{\mathrm{a}}$ \\
\hline Efeito & ns & $\mathrm{L}^{*}$ & $\mathrm{Q}^{*}$ & $\mathrm{~ns}$ & $\mathrm{~L}^{*}$ & ns \\
\hline $\mathrm{CV}(\%)$ & \multicolumn{2}{|c|}{1,36} & \multicolumn{2}{|c|}{2,87} & \multicolumn{2}{|c|}{3,14} \\
\hline
\end{tabular}

$\mathrm{BE}=$ balanços eletrolíticos (mEq.kg); $\mathrm{CV}=$ coeficiente de variação; ${ }^{\mathrm{ab}}$ Médias seguidas pela mesma letra para cada característica avaliada, na linha, não diferem entre si pelo teste $\mathrm{F}(\mathrm{P} \geq 0,05)$; ns = não significativo pelo teste $\mathrm{F}(\mathrm{P} \geq 0,05)$; $\mathrm{Q}^{*}=$ efeito quadrático, pelo teste $\mathrm{F}$ da regressão $(\mathrm{P}<0,05)$; $\mathrm{L}^{*}=$ efeito linear, pelo teste $\mathrm{F}$ da regressão $(\mathrm{P}<0,05)$.

Fonte: Elaboração dos autores.

Tabela 6. Equações de regressão dos parâmetros sanguíneos de frangos de corte de 36 a 42 dias de idade alimentados com dietas com diferentes níveis de proteína bruta (PB) e balanços eletrolíticos (BE).

\begin{tabular}{|c|c|c|c|c|}
\hline Parâmetro & Equação de regressão & $\mathrm{R}^{2}$ & Ponto Min & PB \\
\hline $\mathrm{Na} 240$ & $165,22128-1,69166^{*} \mathrm{~PB}$ & 0,92 & & \\
\hline K200 & $89,3274-9,76401 * \mathrm{~PB}+0,28631 * \mathrm{~PB}^{2}$ & 0,99 & 6,08 & 17,05 \\
\hline $\mathrm{Cl} 200$ & $12,33199+6,01562 * \mathrm{~PB}$ & 0,56 & & \\
\hline
\end{tabular}

$\mathrm{Na}$ - Sódio $\left(\mathrm{mg} \cdot \mathrm{dL}^{-1}\right) ; \mathrm{K}=$ Potássio $\left(\mathrm{mg} \cdot \mathrm{dL}^{-1}\right) ; \mathrm{Cl}=$ Cloro $\left(\mathrm{mg} \cdot \mathrm{dL}^{-1}\right) ;$ Min - Mínimo.

Fonte: Elaboração dos autores.

A redução nos níveis de $\mathrm{PB}$ não teve efeito $(\mathrm{P} \geq 0,05)$ sobre o crescimento ósseo, determinado pelo Índice de Seedor do fêmur e da tíbia das aves. Também não foram observadas diferenças $(\mathrm{P} \geq 0,05)$ entre as médias dos tratamentos com BE de 200 e 240 mEq. $\mathrm{kg}^{-1}$, para os parâmetros de crescimento ósseo avaliados (Tabela 7).
Estes resultados estão em conformidade aos encontrados por Yalçin, Settar e Dicle(1998)e Vieites et al. (2004) que não encontraram efeito de níveis de PB e BE sobre os parâmetros de desenvolvimento ósseo avaliados. Segundo Zollitsch et al. (1996), a mobilização óssea para atender às necessidades metabólicas de íons é um processo normal, e a perda óssea somente comprometerá a resistência quando houver deficiência prolongada. 
Tabela 7. Índice de Seedor $(\mathrm{mg} / \mathrm{mm})$ do fêmur e da tíbia de frangos de corte de 36 a 42 dias de idade, alimentados com rações com diferentes níveis de proteína bruta (PB) e balanços eletrolíticos (BE).

\begin{tabular}{|c|c|c|c|c|}
\hline \multirow{2}{*}{$\begin{array}{l}\mathrm{PB}(\%) \\
\mathrm{BE}\end{array}$} & \multicolumn{2}{|c|}{ Fêmur } & \multicolumn{2}{|c|}{ Tíbia } \\
\hline & 200 & 240 & 200 & 240 \\
\hline 18,00 & 14,137 & 13,458 & 12,116 & 12,317 \\
\hline 17,28 & 11,027 & 13,368 & 13,572 & 12,212 \\
\hline 16,56 & 12,971 & 7,264 & 11,621 & 12,942 \\
\hline 15,84 & 14,227 & 12,906 & 12,458 & 11,93 \\
\hline Média & $13,090^{\mathrm{a}}$ & $11,743^{\mathrm{a}}$ & $12,442^{\mathrm{a}}$ & $12,352^{\mathrm{a}}$ \\
\hline Efeito & ns & ns & ns & ns \\
\hline CV $(\%)$ & \multicolumn{2}{|c|}{25,02} & \multicolumn{2}{|c|}{5,79} \\
\hline
\end{tabular}

$\mathrm{BE}=$ balanços eletrolíticos (mEq.kg); $\mathrm{CV}=$ coeficiente de variação; ${ }^{\text {ab }}$ Médias seguidas pela mesma letra para cada característica avaliada, na linha, não diferem entre si pelo teste $\mathrm{F}(\mathrm{P} \geq 0,05)$; ns = não significativo pelo teste $\mathrm{F}(\mathrm{P} \geq 0,05)$.

Fonte: Elaboração dos autores.

\section{Conclusões}

Os resultados do presente estudo sugerem cautela quanto à decisão por formulações com menor teor de proteína bruta, mesmo com a suplementação de aminoácidos industriais.

A suplementação com os sais bicarbonato de sódio e cloreto de potássio não se mostrou eficiente em melhorar as características de desempenho das aves, nos valores de $\mathrm{BE}$ estudados, considerando que não foram observadas melhoras de desempenho com aumento do BE das dietas de 200 para 240 mEq. $\mathrm{kg}^{-1}$.

\section{Referências}

BORGES, S. A.; MAIORKA, A.; SILVA, A. V. F. Fisiologia do estresse calórico e a utilização de eletrólitos em frangos de corte. Ciência Rural, Santa Maria, v. 33, n. 5, p. 975-981, 2003.

BRUNO, L. D. G.; FURLAN, R. L.; MALHEIROS, E. B.; MACARI, M. I. V. Influence of early quantitative food restriction on long bone growth at different environmental temperatures in broiler chickens. British Poultry Science, London, v. 41, n. 4, p. 389-394, 2000.

BUFFINGTON, D. E.; COLAZZO-AROCHO, A.; CANTON, G. H.; PITTI, D. Black globe-humidity index (BGHI) as comfort equation for dairy cows. Transactions of the ASAE, New York, v. 24, n. 3, p. 711-714, 1981.

CONHALATO, G. S.; DONZELE, J. L.; OLIVEIRA, R. F. M.; ROSTAGNO, H. S.; FONTES, D. O. Avaliação de rações contendo diferentes níveis de lisina digestível mantendo a relação aminoacídica para pintos de corte na fase de 1 a 21 dias de idade. Revista Brasileira de Zootecnia, Viçosa, v. 29, n. 1, p. 2066-2071, 2000.

DAVENPORT, H. W. ABC do equilíbrio ácido-básico do sangue. 2. ed. São Paulo: Edart, 1972. 84 p.

GOMIDE, E. M.; RODRIGUES, P. B.; BERTECHINI, A. G.; FREITAS, R. T. F.; FASSANI, É. J.; REIS, M. P.; RODRIGUES, N. E. B.; ALMEIDA, E. C. Rações com níveis reduzidos de proteína bruta, cálcio e fósforo com fitase e aminoácidos para frangos de corte. Revista Brasileira de Zootecnia, Viçosa, v. 40, n. 11, p. 24052414, 2011.

JIANG, Q.; WALDROUP, P. W.; FRITTS, C. A. Improving the utilization of diets in crude protein for broiler chicken. 1. Evaluation of special amino acid supplementation to diets low in crude protein. International Journal of Poultry Science, London, v. 4, n. 3, p. 115-122, 2005.

KAMRAN, Z.; SARWAR, M.; NISA, M.; NADEEM, M. A.; MAHMOOD, S.; BABAR, M. E.; AHMED, S. Effect of low-protein diets having constant energy-toprotein ratio on performance and carcass characteristics of broiler chickens from one to thirty-five days of age. Poultry Science, Champaign, v. 87, n. 3, p. 468-474, 2008.

MATOS, M. B.; FERREIRA, R. A.; COUTO, H. P.; SAVARIS, V. D. L.; SOARES, R. T. R. N.; OLIVEIRA, N. T. E. Balanço eletrolítico da dieta e desempenho de frangos em condições naturais de estresse calórico. Arquivo Brasileiro de Medicina Veterinária e Zootecnia, Belo Horizonte, v. 63, n. 6, p. 1461-1469, 2011.

MATOS, M. B.; FERREIRA, R. A.; SAVARIS, V. D. L.; COUTO, H. P.; SOARES, R. T. R. N.; OLIVEIRA, N. T. E. Balanço eletrolítico e redução da proteína bruta 
da ração sobre parâmetros fisiológicos e sanguíneos de frangos de corte no calor. Acta Scientiarum Animal Sciences, Maringá, v. 31, n. 3, p. 243-249, 2009.

MEDEIROS, C. M.; BAÊTA, F. C.; OLIVEIRA, R. F. M.; TINOCO, I. F. F. T.; ALBINO, L. F. T.; CECON, P. R. Efeitos da temperatura, umidade relativa e velocidade do ar em frangos de corte. Revista Engenharia na Agricultura, Viçosa, v. 13, n. 4, p. 277-286, 2005.

MONGIN, P. Recent advances in dietary ânion-cátion balance: applications in poultry. Proceedings of the Nutrition Society, London, v. 40, n. 1, p. 285-294, 1981.

OLIVEIRA, M. C.; ARANTES, U. M.; STRINGHINI, J. H. Efeito do balanço eletrolítico da ração sobre parâmetros ósseos e da cama de frango. Biotemas, Florianópolis, v. 23, n. 1, p. 203-209, 2010.

OLIVEIRA, R. F. M.; DONZELE, J. L.; ABREU, M. L. T.; FERREIRA, R. A.; VAZ, R. G. M. V.; CELLA, P. S. Efeitos da temperatura e da umidade relativa sobre o desempenho e o rendimento de cortes nobres de frangos de corte de 1 a 49 dias de idade. Revista Brasileira de Zootecnia, Viçosa, v. 35, n. 3, p. 797-803, 2006.

OLIVEIRA, W. P.; OLIVEIRA, R. F. M.; DONZELE, J. L.; ALBINO, L. F. T.; MARTINS, M. S.; MAIA, A. P. A. Redução do nível de proteína bruta em rações para frangos de corte em ambiente de termoneutralidade. Revista Brasileira de Zootecnia, Viçosa, v. 40, n. 8, p. 1725-1731, 2011.

OLIVEIRA, W. P.; OLIVEIRA, R. F. M.; DONZELE, J. L.; GOMES, P. C.; MARTINS, M. S.; ASSIS, A. P. Redução do nível de proteína bruta em rações para frangos de corte em ambiente de estresse por calor. Revista Brasileira de Zootecnia, Viçosa, v. 39, n. 5, p. 1092-1098, 2010.

ROSTAGNO, H. S.; ALBINO, L. F. T.; DONZELE, J. L.; GOMES, P. C.; FERREIRA, A. S.; OLIVEIRA, R. F. M.; LOPES, D. C. Tabelas brasileiras para suinos e aves: composição de alimentos e exigências nutricionais. 2. ed. Viçosa: UFV, 2005. 186 p.

ROSTAGNO, H. S.; ALBINO, L. F. T.; DONZELE, J. L.; GOMES, P. C.; FERREIRA, A. S.; OLIVEIRA, R. F. M.; LOPES, D. C. Tabelas brasileiras para suinos e aves: composição de alimentos e exigências nutricionais. 3. ed. Viçosa: Universidade Federal de Viçosa, 2011. 252 p.

SAKOMURA, N. K.; ROSTAGNO, H. S. Métodos de pesquisa em nutrição de monogástricos. Jaboticabal: FUNEP, 2007. $283 \mathrm{p}$.
SARTOR, V.; BAÊTA, F. C.; TINÔCO, I. F. F.; LUZ, M. L. Efeito do resfriamento evaporativo no desempenho de suínos em fase de terminação. Engenharia na Agricultura, Viçosa, v. 11, n. 1-4, p. 58-64. 2003.

SEEDOR, J. G.; QUARRUCCIO, H. A.; THOMPSON, D. D. The bisphosphonate alendronate (MK-217) inhibits bone loss due to ovariectomy in rats. Journal of Bone and Mineral Research, v. 6, n. 4, p. 339-346, 1991.

UNIVERSIDADE FEDERAL DE VIÇOSA - UFV. SAEG: sistema para análises estatísticas e genéticas versão 9.0. Viçosa: UFV, 2005.

VASCONCELLOS, C. H. F.; FONTES, D. O.; VIDAL, T. Z. B.; LARA, L. J. C.; RODRIGUES, P. B.; VASCONCELOS, R. J. C. Efeito de diferentes níveis de proteína bruta sobre o desempenho e composição de carcaça de frangos de corte machos de 21 a 42 dias de idade. Ciência e Agrotecnologia, Lavras, v. 34, n. 4, p. 1039-1048, 2010.

VIEITES, F. M.; FRAGA, A. L.; MORAES, G. H. K.; VARGAS JÚNIOR, J. G.; NALON, R. P.; CORRÊA, G. S. S.; NUNES, R. V. Cálcio, fósforo e proteína total no sangue de frangos de corte em função de níveis de balanço eletrolítico da ração. Arquivo Brasileiro de Medicina Veterinária e Zootecnia, Belo Horizonte, v. 63, n. 4, p. 887-894, 2011 b.

VIEITES, F. M.; FRAGA, A. L.; SOUZA, C. S.; ARAÚJO, G. M.; VARGAS JÚNIOR, J. G. V.; NUNES, R. V.; CORREA, G. S. S. Desempenho de frangos de corte alimentados com altos valores de balanço eletrolítico em região de clima quente. Arquivo Brasileiro de Medicina Veterinária e Zootecnia, Belo Horizonte, v. 63, n. 2, p. 441-447, 2011a.

VIEITES, F. M.; MORAES, G. H. K.; ALBINO, L. F. T.; ROSTAGNO, H. S.; RODRIGUES, A. C.; SILVA F. Á.; ATENCIO, A. Balanço eletrolítico e níveis de proteína bruta sobre parâmetros sanguíneos e ósseos de frangos de corte aos 21 dias de idade. Revista Brasileira Zootecnia, Viçosa, v. 33, n. 6, p. 1520-1530, 2004.

YALÇIN, S.; SETTAR, P.; DICLE, O. Influence of dietary protein and sex on walking ability and bone parameters of broilers. British Poultry Science, London, v. 39, n. 2, p. 251-256, 1998.

ZOLLITSCH,W.;ZHIQIANG,C.;PEGURI,A.;ZHANG, B.; CHENG, T.; COON, C. Nutrient requirements of laying hens. In: SIMPÓSIO INTERNACIONAL SOBRE EXIGÊNCIAS NUTRICIONAIS DE AVES E SUÍNOS, 1996, Viçosa, MG. Anais... Viçosa, MG: 1996. p. 109159. 